\title{
O CRIME DE VIOLÊNCIA DOMÉSTICA: ATO REITERADO OU NÃO,
} EIS A QUESTÃO

\section{THE CRIME OF DOMESTIC VIOLENCE: REPEATED CONDUCT OR NOT, THAT IS THE QUESTION}

\author{
EL DELITO DE VIOLENCIA DOMÉSTICA: ACTO REITERADO O NO, ESA ES LA \\ PREGUNTA
}

\author{
Nuno Caetano Lopes de Barros Poiares \\ https://orcid.org/0000-0002-9325-0206 / http:// lattes.cnpq.br/8334044374958840 / nunopoiares@hotmail.com \\ ICPOL - Centro de Investigação \\ Instituto Superior de Ciências Policiais e Segurança Interna
}

Portugal

\begin{abstract}
RESUMO
A violência doméstica é um problema social que ganhou uma visibilidade acrescida no século XXI, através de uma consciencialização da sociedade portuguesa para a importância do combate e da prevenção desse fenômeno. No entanto, persistem dúvidas, junto dos operadores do Direito, maxime os magistrados, advogados e policiais, quanto ao preenchimento dos pressupostos da ação típica desse crime, mormente a necessidade de uma reiteração de condutas. No presente artigo procede-se a uma análise legal e jurisprudencial com o objetivo de se reduzir a subjetividade conceitual e contribuir para uma melhor operacionalização na prática jurídica. Concluímos que a jurisprudência tem caminhado com base em conceitos que potenciam a complexidade da discussão e que não permitem uma clarificação do tema sub judice.
\end{abstract}

Palavras-chave: Conduta reiterada. Dignidade humana. Direito penal. Violência doméstica.

\section{ABSTRACT}

Domestic violence is a social problem that gained increased visibility in the 21st century, through an awareness of Portuguese society about the importance of combating and preventing this phenomenon. However, doubts persist, among the operators of the Law, maxime the magistrates, lawyers and policemen, as to the fulfillment of the assumptions of the typical action of this crime, especially the need for a reiteration of conducts. In this article, a legal and jurisprudential analysis is carried out in order to reduce conceptual subjectivity and contribute to a better operationalization in legal practice. We conclude that the jurisprudence has chosen to base its decisions on concepts that enhance the complexity of the discussion and that do not allow a clarification of the topic under analysis.

Keywords: Repeated conduct. Human dignity. Criminal law. Domestic violence.

\section{RESUMEN}

La violencia doméstica es un problema social que ganó visibilidad en el siglo XXI, a través de la conciencia de la sociedad portuguesa sobre la importancia de combatir y prevenir este fenómeno. Sin embargo, persisten dudas, entre los operadores de la Ley, entre los magistrados, abogados y policías, sobre el cumplimiento de los supuestos de la acción típica de este delito, especialmente la necesidad de una reiteración de conductas. En este artículo, se realiza un análisis jurídico y jurisprudencial para reducir la subjetividad conceptual y contribuir a una mejor operatividad en la práctica jurídica. Concluimos que la jurisprudencia ha elegido basar sus decisiones en conceptos que mejoran la complejidad de la discusión y que no permiten una aclaración del tema bajo análisis.

Palabras clave: Conducta repetida. Dignidad humana. Derecho penal. Violencia doméstica. 


\section{SUMÁRIO}

INTRODUÇÃO; 10 CRIME DE VIOLÊNCIA DOMÉSTICA; 2 ATO REITERADO OU NÃO, EIS A QUESTÃO; 3 DA CONDUTA REITERADA; 4 DA OFENSA À DIGNIDADE HUMANA; CONCLUSÃO; REFERÊNCIAS.

\section{INTRODUÇÃO}

A pertinência do tema sub judice é inquestionável do ponto de vista da dialética entre os operadores do Direito e a sociedade, materializada em políticas públicas, como a Estratégia Nacional para a Igualdade e a não Discriminação, aprovada pela Resolução do Conselho de Ministros n. ${ }^{\circ}$ 61/2018, de 21 de maio; ou os Planos Nacionais contra a Violência Doméstica, que foram emanados desde 1999, procurando estabelecer os vetores de orientação para os magistrados e as forças de segurança (entre outros atores) de forma a prevenir e combater este fenómeno, incluindo a melhoria no serviço prestado às vítimas ${ }^{1}$.

Até ao ano de 2007 a tipificação do crime de violência doméstica (VD) pressupunha, em regra, uma conduta reiterada por parte do agente, algo que passou a ser irrelevante face à nova letra do artigo $152 .^{\circ}$ do Código Penal (CP). No entanto, a jurisprudência tem demonstrado que nem todo o ato singular pode ser enquadrado como VD, por não ser atendível como uma ofensa à dignidade humana, o que tem suscitado várias dúvidas nos mandatos profissionais, desde logo aquando da atuação policial que, face à incapacidade de objetivar legalmente determinados comportamentos jurídico-penais, tendem a tipificar os mesmos como VD, ainda que, mais tarde, o Ministério Público venha a ter entendimento diverso².

0 artigo assenta num raciocínio lógico-dedutivo e apresenta uma abordagem à evolução do quadro legal da violência doméstica em Portugal, a partir do I Plano Nacional Contra a Violência Doméstica, aprovado pela Resolução do Conselho de Ministros n. ${ }^{\circ}$ 55/99, de 15 de junho; e uma análise jurisprudencial relativamente aos pressupostos para a materialização do ato de violência doméstica, em particular a reiteração, enquanto crime com uma tutela penal

\footnotetext{
1 LEMOS, Inês. Proteção policial da vítima: avaliação do risco do agressor em cenários de violência doméstica, 2019.

2 Estas dúvidas são partilhadas pelo Ministério Público, como se depreende do ponto 4 da diretiva emanada recentemente (dez. 2019) pela Procuradoria-Geral da República que refere o seguinte: sempre que, aquando do registo de inquérito, se suscita dúvida quanto à qualificação como violência doméstica da factualidade subjacente, deve aquela prevalecer, mantendo-se a mesma até ao momento em que seja inequívoco enquadramento diverso. Vide PORTUGAL. Diretiva $n .^{\circ} 5 / 2019$, de 4 de dezembro - estabelece procedimentos específicos a observar pelos magistrados e agentes do Ministério Público na área da violência doméstica. In: Diário da República Eletrónico. Disponível em: https://dre.pt/home//dre/126870404/details/maximized. Acesso em: 18 fev. 2020.
} 
especial reforçada, baseada na dignidade humana, conceito amplo que continua a gerar interpretações diversas e com repercussões nos mandatos profissionais.

\section{O CRIME DE VIOLÊNCIA DOMÉSTICA}

0 atual Código Penal Português, aprovado na sua versão original pelo Decreto-Lei $n .^{\circ}$ $400 / 82$, de 3 de setembro, introduziu o crime de "Maus-tratos ou sobrecarga de menores e de subordinados ou entre cônjuges", constituindo a primeira designação mais aproximada do crime previsto hoje no artigo 152. ${ }^{\circ}$ Em 1995, o CP, através do Decreto-Lei n. ${ }^{\circ} 48 / 95$, de 15 de março, passou a prever a aplicação de pena de prisão aos crimes de maus-tratos físicos ou psíquicos infligidos pelo cônjuge ou quem com ele conviver em condições análogas às dos cônjuges no crime designado de "Maus-tratos ou sobrecarga de menores, de incapazes ou do cônjuge”. Com a Lei $n .^{\circ} 7 / 2000$, de 27 de maio, que procede à quinta alteração do Decreto-Lei acima mencionado, a natureza do crime, agora denominado de "Maus-tratos e infração de regras de segurança", alterou-se para pública, passando a prever o alargamento ao progenitor de ascendente comum em $1 .^{\circ}$ grau $^{3}$. A modificação da natureza do crime permite ao Estado acionar a ação penal sem o consentimento da vítima. A partir deste momento, de acordo com o artigo 244. ${ }^{\circ}$ do Código de Processo Penal (CPP), qualquer pessoa que tenha conhecimento do crime, pode denunciá-lo ao Ministério Público (MP), a outra autoridade judiciária ou aos Órgãos de Polícia Criminal (OPC). Contudo, a denúncia do crime é obrigatória para as entidades policiais e para os funcionários, na aceção do artigo $386 .^{\circ}$ do $\mathrm{CP}$, se tomarem conhecimento do crime no exercício das suas funções e por causa delas, sendo que o MP tem legitimidade para promover o processo penal, independentemente da vontade da vítima, de acordo com o artigo $48 .^{\circ}$ do $\mathrm{CPP}^{4}$.

Com a reforma penal introduzida pela Lei n. ${ }^{\circ} 59 / 2007$, de 4 de setembro, a epígrafe do artigo 152. ${ }^{\circ}$ passou a designar-se violência doméstica. Este crime corresponde a qualquer ato, conduta ou omissão que sirva para infligir, de modo reiterado ou não, sofrimentos físicos, sexuais, mentais ou económicos, de modo direto ou indireto (podendo incluir castigos corporais, privações da liberdade e ofensas sexuais), a qualquer pessoa que habite no mesmo agregado doméstico privado. 0 arguido, ainda que não habite no mesmo agregado doméstico privado que a vítima, passa a ser punido se infligir os maus-tratos a cônjuge ou ex-cônjuge, a pessoa que

\footnotetext{
${ }^{3}$ MORAIS, Teresa. Violência doméstica: o reconhecimento jurídico da vítima. Coimbra: Almedina, 2019. p. 38.

${ }^{4}$ LEMOS, Inês. Proteção policial da vítima: avaliação do risco do agressor em cenários de violência doméstica. Dissertação de mestrado em Ciências Policiais. Lisboa: ISCPSI, 2019.
} 
mantenha ou tenha mantido uma relação de namoro ou análoga à dos cônjuges e a progenitor de descendente comum em $1 .^{\circ}$ grau. Relativamente às pessoas particularmente indefesas, em razão da idade, deficiência, doença, gravidez ou dependência económica, estas têm de coabitar com o mesmo de acordo com a alínea d) do artigo $152 .^{\circ}$ do CP. As relações de namoro ou relações análogas às dos cônjuges, foram incluídas em 2013, com a 29. alteração ao CP, por força da Lei n. ${ }^{\circ}$ 19/2013, de 21 de fevereiro. A 45. ${ }^{a}$ alteração ao CP, aprovada pela Lei n. ${ }^{\circ}$ 16/2018, de 27 de março, passou a integrar na previsão de qualificação do homicídio os crimes cometidos no âmbito de uma relação de namoro, reforçando a sua proteção jurídico-penal.

$\mathrm{Na}$ sequência do previsto no artigo $152 .^{\circ}$, são agravadas todas as situações praticadas contra menores ou na presença dos mesmos, seja em domicílio comum ou no domicílio da vítima; assim como a difusão de dados pessoais, em imagem ou som, da intimidade da vida privada das vítimas sem o seu consentimento, através da internet ou de outros meios e se decorrentes dos maus-tratos resultem ofensas à integridade física grave ou no extremo a morte, conforme previsto na Lei . $^{\circ} 44 / 2018$, de 9 de agosto, configurando a $46 .^{a}$ alteração ao CP, que altera o artigo $152 .^{\circ}$. Como forma de prevenir a reincidência do crime, estão previstas penas acessórias ao arguido, como a proibição de contacto com a vítima, incluindo o afastamento da residência ou do local de trabalho da mesma. Esta pena prevê a fiscalização do arguido por meios técnicos de controlo à distância. Acrescenta-se ainda a proibição de uso e porte de armas, bem como a obrigação de frequência de programas específicos de prevenção da violência doméstica. Acresce que surgiram diversos esforços legislativos referentes à violência doméstica, nomeadamente a Lei n. ${ }^{\circ}$ 61/91, de 13 de agosto, com o objetivo de garantir a proteção legal adequada às mulheres vítimas de violência doméstica, bem como os Planos Nacionais contra a Violência Doméstica ${ }^{5}$, que visam a eliminação desta problemática, como fator indispensável à constituição de uma sociedade verdadeiramente democrática, assente nos princípios da dignidade da pessoa humana, da igualdade e da justiça como pilares fundamentais do Estado de

\footnotetext{
5 I PNCVD (1999-2002) aprovado pela Resolução do Conselho de Ministros n. ${ }^{\circ}$ 55/99, de 15 de junho; II PNCVD (2003-2006) aprovado pela Resolução do Conselho de Ministros n. ${ }^{\circ} 55 / 99$, de 15 de junho; III PNCVD (2007-2010), aprovado pela Resolução do Conselho de Ministros n. ${ }^{\circ} 83 / 2007$, de 22 de junho; IV PNCVD (2011-2013), aprovado pela Resolução do Conselho de Ministros n. ${ }^{\circ} 100 / 2010$, de 17 de dezembro; $V$ PNCVD (2014-2017), aprovado pela Resolução do Conselho de Ministros n. ${ }^{\circ}$ 102/2013, de 31 de dezembro.
} 
direito democrático ${ }^{6}$. Desde 1998 que a prevenção da violência doméstica também passou a integrar o quadro de competências dos conselhos municipais de segurança ${ }^{7}$.

Existem vários dispositivos legais com o objetivo de proteger as vítimas de violência doméstica em Portugal $^{8}$, como o regime jurídico para a indemnização das vítimas de crimes violentos, aprovado pelo Decreto-Lei n. ${ }^{\circ}$ 423/91, de 30 de outubro e o regime de indemnização das vítimas de violência conjugal, aprovado pela Lei $n .^{\circ} 129 / 99$, de 20 de agosto, ambos posteriormente revogados pela Lei n. ${ }^{0} 104 / 2009$, de 14 de setembro, que foi alterada pela Lei n. ${ }^{\circ} 121 / 2015$, de 1 de setembro e aprova o regime de concessão de indemnização às vítimas de crimes violentos e de violência doméstica. A Lei n. ${ }^{\circ}$ 107/99, de 3 de agosto, aprova a criação de uma rede pública de casas de apoio a mulheres vítimas de violência. Esta disposição legal foi revogada pela Lei $n .^{\circ} 112 / 2009$, de 16 de setembro, alterada pela Lei n. ${ }^{\circ}$ 24/2017, de 24 de maio e estabelece o regime jurídico aplicável à prevenção da violência doméstica, à proteção e à assistência das suas vítimas. Relativamente às casas abrigo, o Decreto regulamentar $\mathrm{n} .^{\circ}$ 1/2006, de 25 janeiro, regula as condições de organização, funcionamento e fiscalização das casas de abrigo, que integram a rede pública de casas de apoio a mulheres vítimas de violência.

Em relação às medidas de proteção de testemunhas em processo penal, estas vêm estatuídas pelo Decreto-Lei n. ${ }^{\circ} 190 / 2003$, de 22 de agosto, alterado pelo Decreto-Lei n. ${ }^{\circ}$ 227/2009, de 14 de setembro, que regulamenta a Lei n. ${ }^{\circ}$ 93/99, de 14 de julho, posteriormente alterada pela Lei $n .^{\circ}$ 42/2010, de 3 de setembro. Na senda do reforço da segurança da vítima a Assembleia da República emitiu a Resolução n. ${ }^{\circ}$ 67/2017 a recomendar ao Governo que reforce as medidas para a prevenção da violência doméstica, a proteção e assistência às suas vítimas. Para o efeito, as forças de segurança passaram a realizar a inventariação de todas as salas de atendimento à vítima nas várias esquadras e postos do país.

A Portaria n. ${ }^{\circ}$ 220-A/2010, de 16 de abril, alterada pela Portaria n. ${ }^{\circ} 63 / 2011$, de 3 de fevereiro, veio estabelecer as condições de utilização inicial dos meios técnicos de teleassistência, previstos nos números 4 e 5 do artigo $200^{\circ}$ e dos meios técnicos de controlo à distância previstos no artigo $35 .^{\circ}$, ambos da Lei n. ${ }^{\circ} 112 / 2009$, de 16 de setembro, de forma a garantir medidas de afastamento do agressor da casa de morada comum com a vítima. Nesse mesmo ano, entrou em vigor a Portaria $n .^{\circ} 229-\mathrm{A} / 2010$, de 23 de abril, que aprovou os modelos

\footnotetext{
6 PORTUGAL. I Plano Nacional Contra a Violência Doméstica (1999-2002) aprovado pela Resolução do Conselho de Ministros n. ${ }^{\circ}$ 55/99, de 15 de junho. In: Diário da República Eletrónico, Lisboa. Disponível em: https://dre.pt/pesquisa/-/search/308998/details/maximized. Acesso em: 18 fev. 2020.

7 Lei n. ${ }^{\circ} 33 / 98$, de 18 de julho, alterada pelo Decreto-Lei n. ${ }^{\circ} 32 / 2019$, de 4 de março, em conjugação com Decreto-Lei n. ${ }^{\circ} 101 / 2018$, de 29 de novembro.

${ }^{8}$ MORAIS, Teresa. Violência doméstica: o reconhecimento jurídico da vítima. Coimbra: Almedina, 2019.
} 
de documentos comprovativos da atribuição do estatuto de vítima, também presente na Lei $\mathrm{n}^{\circ}$ 112/2009, de 16 de setembro, nos números 1 e 3 do artigo $14 .^{\circ}$. A Lei n. ${ }^{\circ} 130 / 2015$, de 4 de setembro, que procedeu à $23 .^{a}$ alteração ao CPP, aprovou a atribuição do estatuto de vítima especialmente vulnerável e transpôs a Diretiva 2012/29/UE do Parlamento Europeu e do Conselho, de 25 outubro de 2012, que estabelece normas relativas aos direitos, ao apoio e à proteção das vítimas da criminalidade.

De acordo com a Lei de Política Criminal para o biénio de 2017-2019, a violência doméstica consta como um dos fenómenos criminais de prevenção prioritária, conforme previsto na alínea f) do artigo $2 .^{\circ}$ da Lei n. ${ }^{\circ} 96 / 2017$, de 23 de agosto. Atualmente, verifica-se um novo ciclo programático, alinhado com a Agenda 2018-2030 para o Desenvolvimento Sustentável, que assenta em três Planos Nacionais de Ação, com objetivos estratégicos em matéria de igualdade entre mulheres e homens, prevenção e combate à violência contra as mulheres e violência doméstica e combate à discriminação em razão da orientação sexual, identidade de género e características sexuais.

Foram ainda emanadas algumas orientações e documentos provenientes das forças de segurança, bem como da Procuradoria-Geral da República (PGR), com o objetivo de esclarecer procedimentos de cariz funcional ${ }^{9}$. As sucessivas alterações ao direito da violência doméstica levaram a Polícia a adaptar os seus procedimentos aos dispositivos do direito penal material e processual. Assim, nos casos de denúncia numa esquadra (pela vítima) os órgãos de polícia criminal (OPC) elaboram as seguintes peças processuais: auto de denúncia padronizado (por VD), notificação da vítima para comparência em estabelecimento hospitalar, assim como nos termos dos artigos $75 .^{\circ}, 76 .^{\circ}$ e $77 .^{\circ}$ do Código de Processo Penal; notificação para comparência na Esquadra de Investigação Criminal (EIC), para ser ouvida em inquérito; estatuto da vítima e avaliação do risco (RVD). Nos casos de flagrante delito, o OPC elabora um auto de notícia de detenção (por VD) com todo o expediente associado (constituição de arguido, termo de identidade e residência, etc.); notificação da vítima para comparência em estabelecimento hospitalar e nos termos dos artigos $75 .^{\circ}, 76 .^{\circ}$ e $77 .^{\circ}$ do CPP; notificação da vítima para comparência na EIC para ser ouvida em inquérito, estatuto da vítima e RVD. Nos casos em que

\footnotetext{
${ }^{9}$ E.g. o ofício n. ${ }^{\circ} 3705 / 2006$, de 25 de janeiro de 2006 do Gabinete do PGR, que aborda a entrada em domicílio sem consentimento ou autorização em situações de violência doméstica; a assinatura em 2007, de um protocolo de cooperação entre a PSP e a Associação Portuguesa de Apoio à Vítima (APAV) com o intuito de reforçar a colaboração direta e recíproca na área de apoio à vítima; o ofício n. ${ }^{\circ} 644$ de 26 de janeiro de 2010, da Direção Nacional da PSP, relativamente ao regime jurídico aplicável à prevenção da violência doméstica; o ofício $n .^{\circ} 258 / 2011 / G A J$, de 30 de maio de 2011, do GAJ-DNPSP que versa sobre violência doméstica versus a violência no namoro; entre outros.
} 
estejam envolvidas crianças os elementos das Equipas de Proximidade e Apoio à Vítima da Polícia de Segurança Pública (EPAV-PSP) recorrem às parcerias institucionais para garantirem os cuidados necessários à vítima e às crianças, como hospitais, instituições de apoio a vítimas, casas-abrigo, comissões de proteção de crianças e jovens, Segurança Social, etc. Em todos os casos as EPAV garantem o acompanhamento pós-vitimação, contactando a vítima e o agressor (separadamente), para apurarem novos desenvolvimentos e incutirem um sentimento de controlo no agressor, elaborando um Aditamento para dar conhecimento ao MP.

No entanto, importa referir que muitas das ocorrências encaminhadas pelas forças de segurança para os tribunais são tipificadas erradamente como violência doméstica ${ }^{10}$. $E$ isso devese sobretudo à incapacidade - cada vez mais residual, mas muito evidente - em compreender que nem todo o comportamento ilícito preenche os pressupostos vertidos no artigo $152 .^{\circ}$ do Código Penal. É, por isso, fundamental desenvolver um esforço de permanente supervisão, escrutínio e trabalho próximo com o Ministério Público, por forma a diminuir interpretações enviesadas que, mais tarde, obrigam uma alteração da tipificação.

\section{ATO REITERADO OU NÃO, EIS A QUESTÃO}

Neste momento importa desenvolver uma análise jurisprudencial para percebermos o entendimento dos tribunais relativamente à questão abordada na secção anterior in fine. Vimos que, até à reforma penal de 2007 , existia um pressuposto que estava claramente consolidado no espírito dos profissionais da PSP: para que um facto fosse considerado crime de maus tratos era essencial clarificar a existência de um comportamento ilícito reiterado no tempo. Era uma preocupação evidente, desde logo nas peças processuais elaboradas pelos órgãos de polícia criminal, onde tinha de surgir, necessariamente, uma menção expressa à reiteração, para que fosse dado o encaminhamento adequado a um crime com a natureza pública. Assim, até à entrada em vigor da Lei $n .^{\circ}$ 59/2007, de 4 de setembro o crime de maus tratos pressupunha, em regra, uma reiteração de condutas. Face à nova redação dada ao artigo $152 .^{\circ},{ }^{\circ}{ }^{\circ}$, o referido crime pode ser cometido mesmo que não haja reiteração de condutas, embora só em situações excecionais o comportamento violento único, pela gravidade intrínseca do mesmo, preencha o

\footnotetext{
${ }_{10}$ POIARES, Nuno Caetano Lopes de Barros. Prevenção da criminalidade e da violência doméstica, Como tornar Portugal um país seguro, Lisboa: Bnomics, 2013. ISBN: 978-989-713-064-9, pp. 185-198. Violência, crime e a dimensão simbólica da Lei: o caso da violência doméstica, Atas do VII Congresso Português de Sociologia, FLUP, APS, 2012. O apoio às vítimas de crime: resultados de uma parceria. Estudos de Homenagem ao Juiz Conselheiro A. Neves Ribeiro. Coimbra: Almedina, 2007, pp. 695-703.
} 
tipo de ilícito $^{11}$. E é neste ponto que passaram a existir dúvidas na atuação das forças de segurança. No entanto, a verdade é que, já antes da alteração operada pela Lei n. ${ }^{\circ} 59 / 2007$, de 4 de setembro, a jurisprudência e a doutrina, em geral, entendiam que um único ato de violência podia integrar a prática do crime desde que violasse de forma evidente os bens jurídicos protegidos pela norma, ou seja, a integridade pessoal e a dignidade humana. 0 que não se verificava nas práticas das forças de segurança que buscavam o pressuposto do ato reiterado.

O século XXI representa uma nova fase no combate ao crime de violência doméstica em Portugal. 0 ano de 2000 materializou o momento da viragem, maxime após a aprovação da Lei n. ${ }^{\circ} 7 / 2000$, de 27 de maio, que alterou a legislação penal (art. ${ }^{\circ} 152 .^{\circ}$ ), elevando a natureza pública o crime de maus tratos a cônjuge ou a quem conviver em condições idênticas às dos cônjuges. Deixou, pois, de ser um problema somente das vítimas, mas antes um fenómeno que passou a ser encarado com responsabilidade pela sociedade. Foi Eduardo Correia quem propôs a autonomização do crime de maus tratos nos artigos $166 .^{\circ}$ e $167 .^{\circ}$ do Projeto do $\mathrm{CP}$, sem, no entanto, prever os maus tratos entre cônjuges, ilícito que veio a ser introduzido na redação definitiva do CP pela Comissão Revisora, ficando a constar do n. ${ }^{\circ} 3$ do artigo $153 .^{\circ 12}$.

No entanto, passou a existir a convicção, no seio das forças de segurança e de vários técnicos de ação social de que "tudo era violência doméstica", desde que envolvesse os sujeitos passivos previstos no artigo $152 .^{\circ}$ do CP, ainda que fosse um ato isolado. Nessa senda, surgiram vozes críticas como, por exemplo, que "a violência doméstica era um crime da moda"; que "não fazia sentido a tipificação jurídico-penal da violência doméstica e muito menos a sua natureza pública"; e que os tipos legais existentes no CP eram suficientes"13. No entanto, a jurisprudência defende que, embora o tipo legal abranja ações típicas que já encontram previsão noutros tipos

\footnotetext{
${ }^{11}$ Acórdão do STJ, proc. ${ }^{\circ}$ n. ${ }^{\circ}$ 06P975, 24.04.2006; e FERREIRA, Maria Elisabete. Da intervenção do Estado na questão da violência conjugal em Portugal, dissertação de mestrado em Ciências Jurídico-Civilísticas, FDUCP (Porto). Coimbra: Almedina, 2005. pp. 106-107.

12 NUNES, Carlos Casimiro; MOTA, Maria Raquel. 0 crime de violência doméstica: a al. b) do n. ${ }^{\circ} 1$ do art. $^{\circ}$ $152^{\circ}$ do Código Penal. Revista do Ministério Público, n. ${ }^{\circ} 122$, abril-junho, 2010. p. 134.

13 POIARES, Nuno Caetano Lopes de Barros. Violência doméstica e atividade policial, Anatomia do Crime Revista de Ciências Jurídico-Criminais, n. ${ }^{\circ}$ 9. Lisboa: IDPCC - FDUL. ISSN: 2184-027X, 2019, pp. 59-75. A letra e os espíritos da lei. A violência doméstica em Portugal. Lisboa: Chiado Editora. ISBN: 978-989-516136-2, 2016. Políticas de segurança e as dimensões simbólicas da lei: o caso da violência doméstica em Portugal, tese de doutoramento. Lisboa: ISCTE-IUL. ISBN: 978-989-732-735-3, 2014. Prevenção da criminalidade e da violência doméstica, Como tornar Portugal um país seguro: segurança nacional e prevenção da criminalidade, Lisboa: Bnomics, 2013. ISBN: 978-989-713-064-9, pp. 185-198. A propósito da vitimação secundária vide CHAI, Cássius Guimarães; SANTOS, Jéssica Pereira dos; CHAVES, Denisson Gonçalves. Violência institucional contra a mulher: o Poder Judiciário, de pretenso protetor a efetivo agressor. Revista Eletrônica do Curso de Direito da UFSM, Santa Maria, RS, v. 13, n. 2, p. 640-665, ago. 2018. ISSN 1981-3694. Disponível em: https://periodicos.ufsm.br/revistadireito/article/view/29538. Acesso em: 24 fev. 2020.
} 
legais, o seu fundamento deve ser encontrado na proteção de quem, no âmbito de uma concreta relação interpessoal, vê a sua integridade pessoal, liberdade e segurança ameaçadas com tais condutas, sendo o enfoque colocado na situação relacional existente entre agressor e vítima. 0 verdadeiro traço distintivo deste crime relativamente aos demais onde igualmente se protege a integridade física, a honra ou a liberdade sexual, reside no facto de o tipo legal prever e punir condutas perpetradas por quem afirme e atue, dos mais diversos modos, um domínio, uma subjugação, sobre a pessoa da vítima, sobre a sua vida ou/e sobre a sua honra ou/e sobre a sua liberdade e que a reconduz a uma vivência de medo, de tensão, de subjugação ${ }^{14}$. Nesses casos, há a prática do crime de violência doméstica e não a de crimes de ofensa à integridade física, injúria, ameaça ou sequestro, quando em face do comportamento demonstrado, globalmente considerado, for possível formular o juízo de que o agente demonstrou desprezo, desejo de humilhar, ou especial desconsideração pela vítima ${ }^{15}$. Ou seja, o crime de violência doméstica visa proteger muito mais do que a soma dos diversos ilícitos típicos que o podem preencher ${ }^{16}$, tutelando, não só a integridade física da pessoa individual, mas também a integridade psíquica, protegendo a saúde do agente passivo, tomada no seu sentido mais amplo de ambiente propício a um salutar e digno modo de vida.

Assim, segundo a jurisprudência, se o crime de violência doméstica é punido mais gravemente que os ilícitos de ofensas a integridade física, ameaças, coação, sequestro, difamação e injúrias, etc., e se é distinto o bem jurídico tutelado pela respetiva norma incriminadora, então, para a densificação do conceito de maus tratos não pode servir toda e qualquer ofensa. 0 que importa para efeitos de avaliar se uma conduta é subsumível ao tipo de violência doméstica é atentar no seu caráter violento ou na sua configuração global de desrespeito pela dignidade da pessoa da vítima, ou de desejo de prevalência, dominação e

\footnotetext{
14 PORTUGAL. Acórdão do Tribunal da Relação da Guimarães, processo n. ${ }^{\circ} 121 / 15.5 G A V F L . G 1$, de 4 de junho de 2018. In: Bases Jurídico-Documentais do IGFEJ I.P., Lisboa. Disponível em: http:// www.dgsi.pt/jtrg.nsf/86c25a698e4e7cb7802579ec004d3832/a90e43153a77645d802582ad003df2fd? OpenDocument. Acesso em: 19 fev. 2020. PORTUGAL. Acórdão do Tribunal da Relação de Guimarães, processo n. $^{\circ}$ 77/14.1TAAVV.G1, de 2 de novembro de 2015. In: Bases Jurídico-Documentais do IGFEJ I.P., Lisboa.

Disponível

em: http://www.dgsi.pt/jtrg.nsf/86c25a698e4e7cb7802579ec004d3832/fe9e9c404499b03b80257efa0039fdcd? OpenDocument. Acesso em: $21 \mathrm{fev} .2020$.

15 PORTUGAL. Acórdão do Tribunal da Relação de Guimarães, processo n. ${ }^{\circ}$ 197/12.7GDGMR.G1, de 1 de julho de 2013. In: Bases Jurídico-Documentais do IGFEJ I.P., Lisboa. Disponível em: http://www.dgsi.pt/jtrg.nsf/86c25a698e4e7cb7802579ec004d3832/1d8c5d72bcc7f43280257be40044f38f?O penDocument. Acesso em: 20 fev. 2020.

${ }_{16}$ PORTUGAL. Acórdão do Tribunal da Relação de Coimbra, processo n. ${ }^{\circ} 663 / 16.5$ PBCTB.C1, de 7 de fevereiro de 2018. In: Bases Jurídico-Documentais do IGFEJ I.P., Lisboa. Disponível em: http://www.dgsi.pt/jtrc.nsf/8fe0e606d8f56b22802576c0005637dc/fe62eef9a15eb0888025822f004d20ff?O penDocument. Acesso em: 19 fev. 2020.
} 
controlo sobre a mesma, que se pode manifestar mediante humilhações, provocações, ameaças, insultos, críticas e comentários destrutivos ou vexatórios, restrições arbitrárias a entrada e saída da habitação ou de partes da habitação comum, etc. ${ }^{17}$. Ainda assim, as forças de segurança tipificam e enquadram, muitas das vezes, ocorrências que não encontram eco no espírito do atual artigo $152 .^{\circ}$ do CP: passou-se de um extremo (em que apenas o comportamento reiterado enquadrava o crime de maus-tratos) para o outro (em que todo o facto típico intrafamiliar e inter-relacional com relevância jurídico-penal é considerado violência doméstica, ainda que tenha sido um ato isolado e que não ofenda a dignidade da pessoa humana, nos termos vertidos na jurisprudência. Inclusivamente o Ministério Público difundiu orientações ${ }^{18}$ no sentido de esclarecer que, quando existirem dúvidas, no registo do inquérito, quanto à qualificação como violência doméstica da factualidade subjacente, deve aquela prevalecer, mantendo-se a mesma até ao momento em que seja inequívoco enquadramento diverso.

0 crime de violência doméstica tem, como elementos constitutivos, a inflição de maus tratos físicos ou psíquicos à vítima; e o dolo, o conhecimento e vontade de praticar o facto, com consciência da sua censurabilidade. No entanto, a lei não define o conceito de maus tratos físicos ou psíquicos, apenas esclarece que nele se integram castigos corporais, privações da liberdade e ofensas sexuais. A qualificação de uma determinada ação como mau trato não depende da sua aptidão para preencher um outro tipo de ilícito, da mesma forma que a aptidão de uma determinada ação para preencher o conceito de mau trato não significa a verificação do crime de violência doméstica, tudo dependendo da respetiva situação ambiente e da imagem global do facto $^{19}$, desde logo quando fere a dignidade humana, aspeto essencial para a tipificação do crime de violência doméstica, algo muito evidente na generalidade da

17 PORTUGAL. Acórdão do Tribunal da Relação de Lisboa, processo n. ${ }^{\circ}$ 662/13.9GDMFR.L1, de 5 de julho de 2016. In: Procuradoria-Geral Distrital de Lisboa - Ministério Público, Lisboa. Disponível em: http://www.pgdlisboa.pt/jurel/jur_mostra_doc.php?nid=5097\&codarea=57\&. Acesso em: 19 fev. 2020.; PORTUGAL. Acórdão do Tribunal da Relação de Guimarães, processo n. ${ }^{\circ} 201 / 16.06 \mathrm{GBBCL} . \mathrm{G} 1$, de 6 de fevereiro de 2017. In: Bases Jurídico-Documentais do IGFEJ I.P., Lisboa. Disponível em: http://www.dgsi.pt/jtrg.nsf/86c25a698e4e7cb7802579ec004d3832/b22cdeae54546906802580c7005424b3? OpenDocument. Acesso em: 19 fev. 2020. PORTUGAL. Acórdão do Tribunal da Relação de Guimarães, processo n. ${ }^{\circ}$ 591/11.0PBGMR-G1, de 10 de julho de 2014. In: Bases Jurídico-Documentais do IGFEJ I.P., Lisboa. Disponível em: http://www.dgsi.pt/jtrg.nsf/86c25a698e4e7cb7802579ec004d3832/718002afb36807a180257d4f004b9f9a?0 penDocument. Acesso em: 20 fev. 2020.

18 PORTUGAL. Diretiva n. ${ }^{\circ}$ 5/2019, de 4 de dezembro - estabelece procedimentos específicos a observar pelos magistrados e agentes do Ministério Público na área da violência doméstica. In: Diário da República Eletrónico. Disponível em: https://dre.pt/home/-/dre/126870404/details/maximized. Acesso em: 18 fev. 2020. p. 122.

19 BRANDÃO, Nuno. A tutela penal especial reforçada da violência doméstica. Julgar, n. ${ }^{\circ} 12$ Especial, set./dez., Lisboa, 2010. ISSN 2183-3419. Disponível em: http://julgar.pt/wpcontent/uploads/2015/10/009-024-Tutela-especial-VD.pdf. Acesso em: 17 fev. 2020. p. 19. 
jurisprudência. Os maus-tratos previstos pelo crime de violência doméstica têm subjacente um tratamento degradante ou humilhante de uma pessoa, capaz de eliminar ou limitar claramente a sua condição e dignidade humanas ${ }^{20}$. Esta factualidade complexa reforça as dúvidas na atuação das forças de segurança e nos técnicos de intervenção social, ainda que se verifique uma tendência para dissiparem face à atuação sensibilizadora do MP.

Outro equívoco comum diz respeito à confusão entre os conceitos de violência doméstica, violência conjugal e violência de género. Na verdade, o alcance do artigo $152 .^{\circ}$ do CP vai muito para além da violência ocorrida entre marido e mulher, abrangendo a violência no namoro, relações extraconjugais, com ascendentes, descendentes, entre outros. 0 bem jurídico protegido é complexo, abrangendo a integridade corporal, saúde física e psíquica e a dignidade da pessoa humana, em contexto de relação conjugal ou análoga e mesmo após cessar essa relação. Com a revisão penal de 2007 , deixou de ser necessária a coabitação e de se exigir a ideia de comunhão de cama e habitação, mas não pode deixar de se exigir um caráter mais ou menos estável de relacionamento amoroso, aproximado ao da relação conjugal de cama e habitação ${ }^{21}$. Mas o namoro, tal como a relação análoga à dos cônjuges, deve ser caracterizada por sólidos elementos fácticos que a comprovem ${ }^{22}$ e basear-se em relações sentimentais, íntimas e tendencialmente estáveis ou duradouras, que ultrapassam a mera amizade ou relações fortuitas, não se exigindo um projeto futuro de vida em comum, na medida em que as relações de namoro não têm, em princípio, a pretensão de preencher todas as características associadas à conjugalidade. A existência de duas pessoas numa relação de namoro exige ainda a dualidade da aceitação e vontade real de participação e permanência nesse vínculo sentimental ${ }^{23}$.

20 PORTUGAL. Acórdão do Tribunal da Relação do Porto, processo n. ${ }^{\circ} 368 / 09.3 P Q P R T . P 1$, de 29 de fevereiro de 2012. In: Bases Jurídico-Documentais do IGFEJ I.P., Lisboa. Disponível em: http://www.dgsi.pt/jtrp.nsf/d1d5ce625d24df5380257583004ee7d7/6ac6ded8719a82c5802579c00058c67d? OpenDocument. Acesso em: 20 fev. 2020..

${ }^{21}$ PORTUGAL. Acórdão do Tribunal da Relação de Coimbra, processo n. ${ }^{\circ} 632 / 10.9 P B A V R . C 1$, de 24 de abril de 2012. In: Bases Jurídico-Documentais do IGFEJ I.P., Lisboa. Disponível em: http://www.dgsi.pt/jtrc.nsf/8fe0e606d8f56b22802576c0005637dc/fb9e3149c4a427ce802579ff003c61bf?O penDocument. Acesso em: 20 fev. 2020.

22 PORTUGAL. Acórdão do Tribunal da Relação do Porto, processo n. ${ }^{\circ}$ 3299/14.1TAMTS.P1, 30 de setembro de 2015. In: Bases Jurídico-Documentais do IGFEJ I.P., Lisboa. Disponível em: http://www.dgsi.pt/jtrp.nsf/56a6e7121657f91e80257cda00381fdf/46695696a87b292c80257edd0052e3fa?O penDocument. Acesso em: 21 fev. 2020.

${ }^{23}$ PORTUGAL. Acórdão do Tribunal da Relação de Évora, processo n. ${ }^{\circ}$ 9/17.5GBABF.E1, de 26 de julho de 2018. In: Bases Jurídico-Documentais do IGFEJ I.P., Lisboa. Disponível em: http:// www.dgsi.pt/jtre.nsf/134973db04f39bf2802579bf005f080b/1265873ec18fb1418025830d0034a34b?O penDocument. Acesso em: 19 fev. 2020. 
Integra ainda um crime de maus tratos a conduta de quem desfere bofetadas na face de um filho menor ${ }^{24}$, com tal violência que causaram marcas dos dedos na região atingida. Assim como constitui um crime de maus tratos o comportamento de quem aplicou pancadas com um cinto nas costas da mesma criança, com tal violência que provocou na vítima, dores, humilhação e equimoses ${ }^{25}$. Acresce que a relação extraconjugal também tem reflexos no domínio da valoração criminal ${ }^{26}$.

\section{DA CONDUTA REITERADA}

A generalidade da jurisprudência refere que, o que está em causa, no crime de violência doméstica, não é a punição autónoma de cada um dos atos que integram o conceito de violência doméstica, mas um comportamento reiterado ${ }^{27}$. Na verdade, a doutrina chegou a debater se seria de exigir ou não a reiteração como elemento integrador do crime de maus tratos. Assim, Maia Gonçalves ${ }^{28}$, em anotação ao artigo $152 .^{\circ}$, na redação resultante da revisão operada pelo Decreto-Lei n. ${ }^{\circ}$ 48/95, de 15 de março, alterada pela Lei n. ${ }^{\circ} 7 / 2000$, de 27 de maio, defendeu que o crime de ofensa à integridade física podia ser cometido através de um só ato, enquanto o crime de maus tratos pressupunha a reiteração das condutas, de modo a inculcar um caráter de habitualidade. No mesmo sentido, Leal-Henriques e Simas Santos afirmavam que não bastava uma ação isolada do agente para que se preenchesse o tipo, mas também não se exigia habitualidade da conduta, defendendo que o crime se realizava com a reiteração do comportamento, em determinado período. Taipa de Carvalho afirmava igualmente que o tipo de

\footnotetext{
${ }^{24}$ A propósito das consequências jurídicas para os menores vide SILVA, Hugo Daniel da Cunha Lança. Já não te amo: o que fazemos à criança? Revista Eletrônica do Curso de Direito da UFSM, Santa Maria, RS, v. 14, n. 2, e34907, maio./ago. 2019. ISSN 1981-3694. DOI: http://dx.doi.org/10.5902/1981369434907. Disponível em: https://periodicos.ufsm.br/revistadireito/article/view/34907. Acesso em: 16 fev. 2020.

${ }_{25}$ PORTUGAL. Acórdão do Tribunal da Relação de Lisboa, processo n. ${ }^{\circ} 356 / 17.6 G A C S C . L 1-3$, de 10 de outubro de 2018. In: Bases Jurídico-Documentais do IGFEJ I.P., Lisboa. Disponível em: http://www.dgsi.pt/jtrl.nsf/33182fc732316039802565fa00497eec/cb1e03ee51b739a18025832e004c3394?O penDocument. Acesso em: 19 fev. 2020.

26 PORTUGAL. Acórdão do Tribunal da Relação do Porto, processo n. ${ }^{\circ}$ 18/15.9GAPRD.P1, de 7 de julho de 2016. In: Bases Jurídico-Documentais do IGFEJ I.P., Lisboa. Disponível em: http://www.dgsi.pt/jtrp.nsf/56a6e7121657f91e80257cda00381fdf/c99b6c24a3986256802580250045612d?O penDocument. Acesso em: 19 fev. 2020.

27 PORTUGAL. Acórdão do Tribunal da Relação de Guimarães, processo n. ${ }^{\circ} 1631 / 12.1$ PBBRG.G1, de 23 de setembro de 2013. In: Bases Jurídico-Documentais do IGFEJ I.P., Lisboa. Disponível em: http://www.dgsi.pt/jtrg.nsf/86c25a698e4e7cb7802579ec004d3832/81d92a262ae8155d80257c000047cf88? OpenDocument. Acesso em: 20 fev. 2020.

28 GONÇALVES, Maia. Código Penal Português: Anotado e Comentado, 17. ${ }^{a}$ edição. Coimbra: Almedina, 2005. p. 551.
} 
crime em análise pressupunha, segundo a ratio da autonomização deste crime, uma reiteração das respetivas condutas. Um tempo longo entre dois ou mais dos referidos atos afastaria o elemento reiteração ou habitualidade pressuposto, implicitamente, por este tipo de crime. Por outro lado, o saudoso Augusto Silva Dias referia que não devia entender-se por reiteração o mesmo que continuidade criminosa, bastando-se aquela com uma ação plúrima e repetida, como uma sova. Manuela Valadão e Silveira, citando o acórdão do STJ de 14-11-1997, defendeu igualmente que os maus tratos não implicam repetições reiteradas de ofensas, podendo o crime ser preenchido com uma única conduta agressiva ${ }^{29}$.

Atualmente, o segmento normativo "de modo reiterado ou não", introduzido no corpo do artigo $152 .^{\circ}$ do CP pela Reforma Penal de 2007, é unívoco no sentido de que pode bastar um só comportamento para a condenação ${ }^{30}$. O legislador alargou o âmbito das condutas tipicamente relevantes da VD, prevendo-se que, para o preenchimento do tipo legal, a inflição de maus tratos pode concretizar-se de modo reiterado ou não. Pode-se afirmar que, com essa formulação, foi acolhido o entendimento segundo o qual um só ato de ofensas corporais configura um crime de VD, não sendo, assim, um crime de execução continuada, falando-se em factos reiterados, i.e. ações adequadas no seu conjunto a produzir o resultado. Entende-se, assim, que a reiteração de factos deve ser globalmente apreciada e valorada como integrando um comportamento repetido, dominado por um único sentido de desvalor jurídico-social e que consubstancia um só crime de $V^{31}$. Admite-se, assim, que um comportamento singular bastará para integrar o crime quando assuma uma dimensão manifestamente ofensiva da dignidade pessoal, não sendo necessária a reiteração de comportamentos ${ }^{32}$.

29 PORTUGAL. Acórdão do Supremo Tribunal de Justiça, proc. ${ }^{\circ}$ n. ${ }^{\circ} 07 \mathrm{P} 3861$, de 2 de julho de 2008 . In: Bases Jurídico-Documentais do IGFEJ I.P., Lisboa. Disponível em: http://www.dgsi.pt/jstj.nsf/954f0ce6ad9dd8b980256b5f003fa814/99a7b561df2ec602802574970030add9?0 penDocument. Acesso em: 18 fev. 2020.

30 PORTUGAL. Acórdão do Tribunal da Relação de Évora, processo n. ${ }^{\circ}$ 228/13.3TASTR.E1, de 20 de janeiro de 2015. In: Bases Jurídico-Documentais do IGFEJ I.P., Lisboa. Disponível em: http://www.dgsi.pt/jtre.nsf/134973db04f39bf2802579bf005f080b/6bfd2f864b23d41880257de100582539?0 penDocument. Acesso em: $21 \mathrm{fev}$. 2020. PORTUGAL. Acórdão do Tribunal da Relação de Guimarães, processo $n .^{\circ}$ 639/08.6GBFLG.G1, de 15 de outubro de 2012. In: Bases Jurídico-Documentais do IGFEJ I.P., Lisboa.

http://www.dgsi.pt/jtrg.nsf/86c25a698e4e7cb7802579ec004d3832/06646d98a1cbe65880257aa0003eed7e? OpenDocument. Acesso em: 20 fev. 2020.

31 PORTUGAL. Acórdão do Tribunal da Relação de Lisboa, processo n. ${ }^{\circ}$ 440/07.4GCTVD.L1-5, de 30 de outubro de 2012. In: Bases Jurídico-Documentais do IGFEJ I.P., Lisboa. Disponível em: http://www.dgsi.pt/jtrl.nsf/33182fc732316039802565fa00497eec/851eaf773a1542eb80257b130037afcd?O penDocument. Acesso em: 20 fev. 2020.

32 PORTUGAL. Acórdão do Tribunal da Relação da Guimarães, processo n. ${ }^{\circ} 1011 / 11.6 G B B C L . G 1$, de 10 de setembro de 2012. In: Bases Jurídico-Documentais do IGFEJ I.P., Lisboa. Disponível em: http://www.dgsi.pt/jtrg.nsf/86c25a698e4e7cb7802579ec004d3832/c8483fd423e134e580257a7e0050830c? 


\section{DA OFENSA À DIGNIDADE HUMANA}

A generalidade da jurisprudência apresenta a ofensa da dignidade humana como elemento justificador da tipificação de um ato singular como violência doméstica. Assim, para a sua perfeição, não se exige que a inflição de maus tratos seja reiterada. Quando, porém, se trate de uma só ofensa, esta só consubstancia mau trato se revelar uma intensidade tal que seja apta e bastante para lesar o bem jurídico protegido (saúde física, psíquica ou emocional), em termos de pôr em causa a dignidade da pessoa ofendida ${ }^{33}$. 0 crime de VD visa proteger, não apenas a saúde mas, antes, ao nível do bem jurídico, a integridade pessoal, prevista no artigo 25. ${ }^{\circ}$ da Constituição da República Portuguesa, ligado à defesa da dignidade da pessoa humana, em todas as suas dimensões. Tendo em conta a definição do tipo legal, verifica-se que o crime de VD exige que os mesmos se traduzam na humilhação da vítima ou numa especial desconsideração pela mesma, um tratamento degradante de uma pessoa, capaz de eliminar ou limitar claramente a sua condição e dignidade humanas ${ }^{34}$.

O bem jurídico protegido no crime de VD abrange a integridade corporal, saúde física e psíquica e a dignidade da pessoa humana, em contexto de relação conjugal ou análoga e,

OpenDocument. Acesso em: 20 fev. 2020. PORTUGAL. Acórdão do Tribunal da Relação de Guimarães, processo n. ${ }^{\circ}$ 197/12.7GDGMR.G1, de 1 de julho de 2013. In: Bases Jurídico-Documentais do IGFEJ I.P., Lisboa. em: http://www.dgsi.pt/jtrg.nsf/86c25a698e4e7cb7802579ec004d3832/1d8c5d72bcc7f43280257be40044f38f?O penDocument. Acesso em: 20 fev. 2020.

33 PORTUGAL. Acórdão do Tribunal da Relação do Porto, processo n. ${ }^{\circ} 156 / 11.7 G A R S D . P 1$, de 22 de janeiro de 2014. In: Bases Jurídico-Documentais do IGFEJ I.P., Lisboa. Disponível em: http://www.dgsi.pt/jtrp.nsf/56a6e7121657f91e80257cda00381fdf/b7b44fe6dd194d5a80257c7700416601?0 penDocument. Acesso em: 20 fev. 2020.

${ }^{34}$ PORTUGAL. Acórdão do Tribunal da Relação de Lisboa, processo n. ${ }^{\circ}$ 3/16.0PAPST.L1-9, de 1 de junho de 2017. In: Bases Jurídico-Documentais do IGFEJ I.P., Lisboa. Disponível em: http://www.dgsi.pt/jtrl.nsf/33182fc732316039802565fa00497eec/533100ea5a275ebf802581360060bd7b?O penDocument. Acesso em: 19 fev. 2020. PORTUGAL. Acórdão do Tribunal da Relação de Lisboa, processo n. ${ }^{\circ}$ 662/13.9GDMFR.L1, de 5 de julho de 2016. In: Procuradoria-Geral Distrital de Lisboa - Ministério Público, Lisboa. Disponível em: http://www.pgdlisboa.pt/jurel/jur_mostra_doc.php?nid=5097\&codarea=57\&. Acesso em: 19 fev. 2020. PORTUGAL. Acórdão do Tribunal da Relação de Guimarães, processo n. ${ }^{\circ}$ 201/16.06GBBCL.G1, de 6 de fevereiro de 2017. In: Bases Jurídico-Documentais do IGFEJ I.P., Lisboa. Disponível em: http://www.dgsi.pt/jtrg.nsf/86c25a698e4e7cb7802579ec004d3832/b22cdeae54546906802580c7005424b3? OpenDocument. Acesso em: 19 fev. 2020. PORTUGAL. Acórdão do Tribunal da Relação do Porto, processo n. ${ }^{\circ}$ 368/09.3PQPRT.P1, de 29 de fevereiro de 2012. In: Bases Jurídico-Documentais do IGFEJ I.P., Lisboa. Disponível em: http://www.dgsi.pt/jtrp.nsf/d1d5ce625d24df5380257583004ee7d7/6ac6ded8719a82c5802579c00058c67d? OpenDocument. Acesso em: 20 fev. 2020. 
atualmente, mesmo após cessar essa relação ${ }^{35}$, admitindo-se que um singular comportamento bastará para integrar o crime quando assuma uma dimensão manifestamente ofensiva da dignidade pessoal ${ }^{36}$. O seu âmbito punitivo abarca os comportamentos que, de forma reiterada ou não, lesam a referida dignidade. O bem jurídico protegido por este tipo legal de crime é a saúde e, por conseguinte, podendo ser afetada por uma diversidade de comportamentos que impeçam ou dificultem o normal desenvolvimento de uma pessoa e/ou afetem a dignidade pessoal e individual ${ }^{37}$. Para a caracterização do crime de VD é relevante que os factos, isolados ou reiterados, praticados no âmbito de uma relação conjugal ou de vida em comum, possuam uma gravidade e importância tais que coloquem a pessoa ofendida numa situação inconciliável com a dignidade e a liberdade necessárias a qualquer membro do casal $^{38}$.

No crime de VD tutela-se, assim, a dignidade humana da vítima ${ }^{39}$. Para a perfeição deste tipo legal, não se exige que a inflição de maus tratos seja reiterada. Quando, porém, se trate de uma só ofensa, esta só consubstancia mau trato se revelar uma intensidade tal que seja apta e bastante para lesar o bem jurídico protegido, em termos de pôr em causa a dignidade da pessoa ofendida; um único ato ofensivo só consubstanciará maus tratos se se revelar de tal modo intenso que ao nível do desvalor seja apto a lesar em grau elevado o bem jurídico pondo em causa a dignidade da pessoa humana ${ }^{40}$. Assim, o que é decisivo, para efeitos de avaliar se uma

35 PORTUGAL. Acórdão do Tribunal da Relação de Coimbra, processo n. ${ }^{\circ} 632 / 10.9$ PBAVR.C1, de 24 de abril de 2012. In: Bases Jurídico-Documentais do IGFEJ I.P., Lisboa. Disponível em: http://www.dgsi.pt/jtrc.nsf/8fe0e606d8f56b22802576c0005637dc/fb9e3149c4a427ce802579ff003c61bf?0 penDocument. Acesso em: 20 fev. 2020.

36 PORTUGAL. Acórdão do Tribunal da Relação da Guimarães, processo n. ${ }^{\circ}$ 1011/11.6GBBCL.G1, de 10 de setembro de 2012. In: Bases Jurídico-Documentais do IGFEJ I.P., Lisboa. Disponível em: http://www.dgsi.pt/jtrg.nsf/86c25a698e4e7cb7802579ec004d3832/c8483fd423e134e580257a7e0050830c? OpenDocument. Acesso em: 20 fev. 2020.

37 PORTUGAL. Acórdão do Tribunal da Relação do Porto, processo n. ${ }^{\circ}$ 2167/10.0PAVNG.P1, de 6 de fevereiro de 2013. In: Bases Jurídico-Documentais do IGFEJ I.P., Lisboa. Disponível em: http://www.dgsi.pt/jtrp.nsf/d1d5ce625d24df5380257583004ee7d7/3868899b1b7f1e3380257b19004b479b? OpenDocument. Acesso em: 20 fev. 2020.

38 PORTUGAL. Acórdão do Tribunal da Relação de Évora, processo n. ${ }^{\circ} 119 / 12.5 G B R M Z . E 1$, de 19 de dezembro de 2013. In: Bases Jurídico-Documentais do IGFEJ I.P., Lisboa. Disponível em: http://www.dgsi.pt/jtre.nsf/134973db04f39bf2802579bf005f080b/2106e3745d56821980257de10056fd27?0 penDocument. Acesso em: 20 fev. 2020.

39 PORTUGAL. Acórdão do Tribunal da Relação de Coimbra, processo n. ${ }^{\circ} 1290 / 12.1$ PBAVR.C1, de 29 de janeiro de 2014. In: Bases Jurídico-Documentais do IGFEJ I.P., Lisboa. Disponível em: http://www.dgsi.pt/jtrc.nsf/8fe0e606d8f56b22802576c0005637dc/091165902546f4ad80257c74003e6dee? OpenDocument. Acesso em: 20 fev. 2020.

${ }^{40}$ PORTUGAL. Acórdão do Tribunal da Relação do Porto, processo n. ${ }^{\circ}$ 156/11.7GARSD.P1, de 22 de janeiro de 2014. In: Bases Jurídico-Documentais do IGFEJ I.P., Lisboa. Disponível em: http://www.dgsi.pt/jtrp.nsf/56a6e7121657f91e80257cda00381fdf/b7b44fe6dd194d5a80257c7700416601?0 penDocument. Acesso em: 20 fev. 2020. PORTUGAL. Acórdão do Tribunal da Relação do Porto, processo n. ${ }^{\circ}$ 648/12.0PIVNG.P1, de 10 de setembro de 2014. In: Bases Jurídico-Documentais do IGFEJ I.P., Lisboa. 
conduta é subsumível ao tipo de violência doméstica é atentar no seu caráter violento ou na sua configuração global de desrespeito pela dignidade da pessoa da vítima, ou de desejo de prevalência, dominação e controlo sobre a mesma.

\section{CONCLUSÃO}

A violência doméstica é um problema social que ganhou uma visibilidade evidente no século XXI, através de uma consciencialização da sociedade portuguesa para a importância do combate e prevenção deste fenómeno. Nessa senda, o legislador penal português desenvolveu um esforço, sobretudo desde 1999, no sentido de sistematizar um quadro legal que correspondesse às necessidades das vítimas. No entanto importa garantir que os procedimentos desenvolvidos pelos operadores, in casu as forças de segurança, os técnicos de apoio social, advogados e magistrados, são os mais adequados face ao dispositivo existente. A presente análise visou contribuir para uma discussão alargada relativamente ao alcance do atual artigo $152 .^{\circ}$ do Código Penal Português.

Vimos que, muitas das ocorrências encaminhadas pela Polícia para os tribunais, são tipificadas erradamente como violência doméstica. E isso deve-se sobretudo à incapacidade em compreender que nem todo o comportamento ilícito preenche os pressupostos deste tipo legal de crime, desde logo porque, em abstrato, nem sempre está em causa a dignidade humana, através de um desejo de humilhação, prevalência e domínio sobre o outro, factos difíceis de sinalizar numa primeira abordagem de um episódio criminal. É, por isso, fundamental desenvolver um esforço de permanente supervisão, escrutínio e trabalho próximo com o Ministério Público, por forma a diminuir interpretações enviesadas que, mais tarde, obrigam uma alteração da tipificação, com consequências diretas nas vítimas que, por exemplo, podem ver, mais tarde, o crime de violência doméstica tipificado como um crime de ofensa à integridade física simples, de natureza semipública, cujo procedimento criminal depende de queixa no prazo de seis meses, o que, em certos casos, já pode ter sido ultrapassado. Acresce que o tipo legal sub judice obriga, como vimos anteriormente, um conjunto de procedimentos adicionais, o que aumenta os custos económicos do crime, pelo que importa garantir que a tipificação é efetuada de forma correta. 
Por fim, como ponto de partida para uma futura linha de investigação, entendemos fundamental o desenvolvimento de um estudo que auxilie os diversos operadores, em particular os polícias, através da estruturação de uma grelha de análise que possa ser aplicada em cada caso concreto, por forma a diminuir o encaminhamento indevido das vítimas e a elaboração incorreta das peças processuais, com base num enquadramento legal errado.

\section{REFERÊNCIAS}

ARAÚJO, Filipa Santos. Ferramentas digitais de prevenção e combate para a violência doméstica no espaço europeu - o caso das aplicações móveis, dissertação de mestrado em Comunicação e Media, p. 20, Leiria: Instituto Politécnico de Leiria, 2019.

BRANDÃO, Nuno. A tutela penal especial reforçada da violência doméstica. Julgar, $n .^{\circ} 12$ Especial, set./dez., Lisboa, 2010. ISSN 2183-3419. Disponível em: http://julgar.pt/wpcontent/uploads/2015/10/009-024-Tutela-especial-VD.pdf. Acesso em: 17 fev. 2020.

CHAI, Cássius Guimarães; SANTOS, Jéssica Pereira dos; CHAVES, Denisson Gonçalves. Violência institucional contra a mulher: o Poder Judiciário, de pretenso protetor a efetivo agressor.

Revista Eletrônica do Curso de Direito da UFSM, Santa Maria, RS, v. 13, n. 2, p. 640-665, ago. 2018. ISSN 1981-3694. Disponível em:

https://periodicos.ufsm.br/revistadireito/article/view/29538. Acesso em: 24 fev. 2020.

FERREIRA, Maria Elisabete. Da intervenção do Estado na questão da violência conjugal em Portugal, dissertação de mestrado em Ciências Jurídico-Civilísticas, FDUCP (Porto). Coimbra: Almedina, 2005.

GONÇALVES, Maia. Código Penal Português: Anotado e Comentado, $17 .^{a}$ edição. Coimbra: Almedina, 2005.

LEMOS, Inês. Proteção policial da vítima: avaliação do risco do agressor em cenários de violência doméstica. Dissertação de mestrado em Ciências Policiais. Lisboa: ISCPSI, 2019.

MORAIS, Teresa. Violência doméstica: o reconhecimento jurídico da vítima. Coimbra: Almedina, 2019.

NUNES, Carlos Casimiro; MOTA, Maria Raquel. O crime de violência doméstica: a al. b) do n. ${ }^{1}$ do art. $^{\circ} 152^{\circ}$ do Código Penal. Revista do Ministério Público, n. ${ }^{\circ} 122$, abril-junho, 2010.

POIARES, Nuno Caetano Lopes de Barros. Violência doméstica e atividade policial, Anatomia do Crime - Revista de Ciências Jurídico-Criminais, n. ${ }^{\circ}$ 9. Lisboa: IDPCC - Faculdade de Direito da Universidade de Lisboa, 2019. pp. 59-75.

POIARES, Nuno Caetano Lopes de Barros. A letra e os espíritos da lei. A violência doméstica em Portugal. Lisboa: Chiado Editora, 2016. 
POIARES, Nuno Caetano Lopes de Barros. Políticas de segurança e as dimensões simbólicas da lei: o caso da violência doméstica em Portugal, tese de doutoramento em Sociologia Política e do Direito. Lisboa: ISCTE-IUL, 2014.

POIARES, Nuno Caetano Lopes de Barros. Prevenção da criminalidade e da violência doméstica, Como tornar Portugal um país seguro: segurança nacional e prevenção da criminalidade, Lisboa: Bnomics, 2013. ISBN: 978-989-713-064-9, pp. 185-198.

POIARES, Nuno Caetano Lopes de Barros. Violência, crime e a dimensão simbólica da Lei: o caso da violência doméstica, Atas do VII Congresso Português de Sociologia, Faculdade de Letras da Universidade do Porto. APS, 2012.

POIARES, Nuno Caetano Lopes de Barros. 0 apoio às vítimas de crime: resultados de uma parceria. Estudos de Homenagem ao Juiz Conselheiro António da Costa Neves Ribeiro. Coimbra: Almedina. ISBN: 978-972-403-044-9, 2007, pp. 695-703.

PORTUGAL. Lei n. ${ }^{\circ} 44 / 2018$, de 9 de agosto: 46 . $^{a}$ alteração ao Código Penal, aprovado pelo Decreto-Lei n. ${ }^{\circ} 400 / 82$, de 23 de setembro, reforça a proteção jurídico-penal da intimidade da vida privada na internet (altera artigos $152 .^{\circ}$ e $197 .^{\circ}$ do Código Penal). In: Diário da República Eletrónico, Lisboa. Disponível em: https://dre.pt/web/guest/pesquisa/-

/search/115946549/details/normal?q=Lei+n.\%C2\%BA\%2044\%2F2018\%2C\%20de+9+de+agosto.

Acesso em: $17 \mathrm{fev} .2020$.

PORTUGAL. Lei n. ${ }^{\circ}$ 16/2018, de 27 de março: $45 .^{a}$ alteração ao CP, aprovado pelo Decreto-Lei n. ${ }^{\circ} 400 / 82$, de 23 de setembro, integrando na previsão de qualificação do homicídio os crimes cometidos no âmbito de uma relação de namoro, reforçando a sua proteção jurídico-penal. In Diário da República Eletrónico, Lisboa. Disponível em: https://dre.pt/web/guest/pesquisa/search/114913769/details/normal?q=Lei+n.\%C2\%BA\%2016\%2 F2018\%2C\%20de+27+de+mar\%C3\%A7o. Acesso em: 17 fev. 2020.

PORTUGAL. Lei n. ${ }^{\circ}$ 19/2013, de 21 de fevereiro: primeira alteração à Lei n. ${ }^{\circ}$ 112/2009, de 16 de setembro, que estabelece o regime jurídico aplicável à prevenção da violência doméstica, à proteção e à assistência das suas vítimas, passando a incluir as relações de namoro no articulado do artigo 152. ${ }^{\circ}$ do Código Penal. In: Diário da República Eletrónico, Lisboa. Disponível em: https://dre.pt/web/guest/pesquisa/search/258498/details/normal?q=Lei+n.\%C2\%BA\%2019\%2F20 13\%2C\%20de+21+de+fevereiro. Acesso em: $18 \mathrm{fev.} 2020$.

PORTUGAL. Lei n. ${ }^{\circ} 112 / 2009$, de 16 de setembro, alterada pela Lei n. ${ }^{\circ} 19 / 2013$, de 21 de fevereiro; a Retificação n. ${ }^{\circ} 15 / 2013$, de 19 de março; a Lei n. ${ }^{\circ} 82-B / 2014$, de 31 de dezembro; a PORTUGAL. Lei n. ${ }^{\circ}$ 129/2015, de 3 de setembro; a Lei n. ${ }^{\circ} 42 / 2016$, de 28 de dezembro; e a Lei n. ${ }^{\circ} 24 / 2017$, de 24 de maio: estabelece o regime jurídico aplicável à prevenção da violência doméstica, à proteção e à assistência das suas vítimas e revoga a Lei n. ${ }^{\circ} 107 / 99$, de 3 de agosto, e o Decreto-Lei n. ${ }^{\circ} 323 / 2000$, de 19 de dezembro. In: Diário da República Eletrónico, Lisboa. Disponível em: https://dre.pt/web/guest/pesquisa/-

/search/490247/details/normal?q=Lei+n.\%C2\%BA\%20112\%2F2009\%2C\%20de+16+de+setembro. Acesso em: 18 fev. 2020.

PORTUGAL. Lei n. ${ }^{\circ}$ 59/2007, 4 de setembro: $23 .^{\text {a }}$ alteração ao CP, aprovado pelo Decreto-Lei n. ${ }^{\circ}$ 400/82, de 23 de setembro. In: Diário da República Eletrónico, Lisboa. Disponível em: 
https://dre.pt/web/guest/pesquisa/search/640142/details/normal?q=Lei+n.\%C2\%BA\%2059\%2F20 07\%2C\%204+de+setembro. Acesso em: 18 fev. 2020.

PORTUGAL. Lei $n .^{\circ} 7 / 2000,27$ de maio: reforça as medidas de proteção a pessoas vítimas de violência, convertendo o procedimento criminal dos maus-tratos, para crime de natureza pública. In: Diário da República Eletrónico, Lisboa. Disponível em: https://dre.pt/pesquisa//search/291937/details/maximized. Acesso em: $18 \mathrm{fev} .2020$.

PORTUGAL. Código Penal, aprovado pelo Decreto-Lei n. ${ }^{\circ} 400 / 82$, de 23 de setembro. In: Diário da República Eletrónico, Lisboa. Disponível em: https://dre.pt/web/guest/pesquisa//search/291937/details/normal?q=Lei+n.\%C2\%BA\%207\%2F2000\%2C\%2027+de+maio. Acesso em: 18 fev. 2020.

PORTUGAL. I Plano Nacional Contra a Violência Doméstica (1999-2002) aprovado pela Resolução do Conselho de Ministros n. ${ }^{\circ}$ 55/99, de 15 de junho. In: Diário da República Eletrónico, Lisboa. Disponível em: https://dre.pt/pesquisa/-/search/308998/details/maximized. Acesso em: 18 fev. 2020.

PORTUGAL. II Plano Nacional Contra a Violência Doméstica (2003-2006) aprovado pela Resolução do Conselho de Ministros n. ${ }^{\circ} 88 / 2003$, de 7 de Julho. In: Diário da República Eletrónico, Lisboa. Disponível em: https://dre.pt/web/guest/pesquisa/-

/search $/ 666708 /$ details/normal?q=Resolu\%C3\%A7\%C3\%A30+do+Conselho+de+Ministros+n.\%C2\%BA \%2088\%2F2003\%2C\%20de+7+de+Julho. Acesso em: 18 fev. 2020.

PORTUGAL. III Plano Nacional Contra a Violência Doméstica (2007-2010), aprovado pela Resolução do Conselho de Ministros n. ${ }^{\circ}$ 83/2007, de 22 de junho. In: Diário da República Eletrónico, Lisboa. Disponível em: https://dre.pt/web/guest/pesquisa/-

/search $/ 638881 /$ details $/$ normal?q=Resolu\%C3\%A7\%C3\%A3o+do+Conselho+de+Ministros+n.\%C2\%BA \%2083\%2F2007\%2C\%20de+22+de+junho. Acesso em: $18 \mathrm{fev} .2020$.

PORTUGAL. IV Plano Nacional Contra a Violência Doméstica (2011-2013), aprovado pela Resolução do Conselho de Ministros n. ${ }^{\circ}$ 100/2010, de 17 de dezembro. In: Diário da República Eletrónico, Lisboa. Disponível em: https://dre.pt/web/guest/pesquisa/-

/search $/ 306432 /$ details/normal?q=Resolu\%C3\%A7\%C3\%A30+do+Conselho+de+Ministros+n.\%C2\%BA \%20100\%2F2010\%2C\%20de+17+de+dezembro. Acesso em: 18 fev. 2020.

PORTUGAL. V Plano Nacional Contra a Violência Doméstica (2014-2017), aprovado pela Resolução do Conselho de Ministros n. ${ }^{\circ}$ 102/2013, de 31 de dezembro. In: Diário da República Eletrónico, Lisboa. Disponível em: https://dre.pt/web/guest/pesquisa/-

/search $/ 483890 /$ details $/$ normal?q $=$ Resolu\%C3\%A7\%C3\%A30+do+Conselho+de+Ministros $+n . \% C 2 \% B A$ \%20102\%2F2013\%2C\%20de+31+de+dezembro. Acesso em: $18 \mathrm{fev} .2020$.

PORTUGAL. Estratégia Nacional para a Igualdade e a Não Discriminação (2018-2030), aprovada pela Resolução do Conselho de Ministros n. ${ }^{\circ} 61 / 2018$, de 21 de maio. In: Diário da República Eletrónico, Lisboa. Disponível em: https://dre.pt/home/-/dre/115360036/details/maximized. Acesso em: 18 fev. 2020.

PORTUGAL. Acórdão do Supremo Tribunal de Justiça, processo n. ${ }^{\circ} 06 \mathrm{P} 975$, de 24 de abril de 2006. In: Bases Jurídico-Documentais do IGFEJ I.P., Lisboa. Disponível em: 
http://www.dgsi.pt/jstj.nsf/954f0ce6ad9dd8b980256b5f003fa814/f4d9a96313f50be08025759a00 3e0842?OpenDocument. Acesso em: 18 fev. 2020.

PORTUGAL. Acórdão do Supremo Tribunal de Justiça, proc. ${ }^{\circ}$ n. ${ }^{\circ} 07 P 3861$, de 2 de julho de 2008. In: Bases Jurídico-Documentais do IGFEJ I.P., Lisboa. Disponível em: http://www.dgsi.pt/jstj.nsf/954f0ce6ad9dd8b980256b5f003fa814/99a7b561df2ec6028025749700 30add9?OpenDocument. Acesso em: 18 fev. 2020.

PORTUGAL. Acórdão do Supremo Tribunal de Justiça, proc. ${ }^{\circ}$ n. ${ }^{\circ} 09 \mathrm{P} 0236$, de 12 de março de 2009. In: Bases Jurídico-Documentais do IGFEJ I.P., Lisboa. Disponível em: http://www.dgsi.pt/jstj.nsf/954f0ce6ad9dd8b980256b5f003fa814/f4d9a96313f50be08025759a00 3e0842?OpenDocument. Acesso em: 20 fev. 2020.

PORTUGAL. Acórdão do Tribunal da Relação do Porto, processo n. ${ }^{\circ}$ 368/09.3PQPRT.P1, de 29 de fevereiro de 2012. In: Bases Jurídico-Documentais do IGFEJ I.P., Lisboa. Disponível em: http://www.dgsi.pt/jtrp.nsf/d1d5ce625d24df5380257583004ee7d7/6ac6ded8719a82c5802579c0 0058c67d?OpenDocument. Acesso em: 20 fev. 2020.

PORTUGAL. Acórdão do Tribunal da Relação de Lisboa, processo n. ${ }^{\circ}$ 440/07.4GCTVD.L1-5, de 30 de outubro de 2012. In: Bases Jurídico-Documentais do IGFEJ I.P., Lisboa. Disponível em: http: //www.dgsi.pt/jtrl.nsf/33182fc732316039802565fa00497eec/851eaf773a1542eb80257b1300 37afcd?OpenDocument. Acesso em: 20 fev. 2020.

PORTUGAL. Acórdão do Tribunal da Relação de Coimbra, processo n. ${ }^{\circ}$ 632/10.9PBAVR.C1, de 24 de abril de 2012. In: Bases Jurídico-Documentais do IGFEJ I.P., Lisboa. Disponível em: http://www.dgsi.pt/jtrc.nsf/8fe0e606d8f56b22802576c0005637dc/fb9e3149c4a427ce802579ff00 3c61bf?OpenDocument. Acesso em: 20 fev. 2020.

PORTUGAL. Acórdão do Tribunal da Relação da Guimarães, processo n. ${ }^{\circ} 1011 / 11.6 G B B C L . G 1$, de 10 de setembro de 2012. In: Bases Jurídico-Documentais do IGFEJ I.P., Lisboa. Disponível em: http: / / www.dgsi.pt/jtrg.nsf/86c25a698e4e7cb7802579ec004d3832/c8483fd423e134e580257a7e0 050830c?OpenDocument. Acesso em: 20 fev. 2020.

PORTUGAL. Acórdão do Tribunal da Relação de Guimarães, processo n. ${ }^{\circ}$ 639/08.6GBFLG.G1, de 15 de outubro de 2012. In: Bases Jurídico-Documentais do IGFEJ I.P., Lisboa. Disponível em: http: //www.dgsi.pt/jtrg.nsf/86c25a698e4e7cb7802579ec004d3832/06646d98a1cbe65880257aa0 003eed7e?OpenDocument. Acesso em: 20 fev. 2020.

PORTUGAL. Acórdão do Tribunal da Relação do Porto, processo n. ${ }^{\circ}$ 2167/10.0PAVNG.P1, de 6 de fevereiro de 2013. In: Bases Jurídico-Documentais do IGFEJ I.P., Lisboa. Disponível em: http://www.dgsi.pt/jtrp.nsf/d1d5ce625d24df5380257583004ee7d7/3868899b1b7f1e3380257b19 004b479b?OpenDocument. Acesso em: 20 fev. 2020.

PORTUGAL. Acórdão do Tribunal da Relação de Guimarães, processo n. ${ }^{\circ}$ 1631/12.1PBBRG.G1, de 23 de setembro de 2013. In: Bases Jurídico-Documentais do IGFEJ I.P., Lisboa. Disponível em: http: //www.dgsi.pt/jtrg.nsf/86c25a698e4e7cb7802579ec004d3832/81d92a262ae8155d80257c00 0047cf88?OpenDocument. Acesso em: 20 fev. 2020.

PORTUGAL. Acórdão do Tribunal da Relação de Guimarães, processo n. 197/12.7GDGMR.G1, de 1 de julho de 2013. In: Bases Jurídico-Documentais do IGFEJ I.P., Lisboa. Disponível em: 
http: / /www.dgsi.pt/jtrg.nsf/86c25a698e4e7cb7802579ec004d3832/1d8c5d72bcc7f43280257be40 044f38f?OpenDocument. Acesso em: 20 fev. 2020.

PORTUGAL. Acórdão do Tribunal da Relação de Évora, processo n. ${ }^{\circ}$ 119/12.5GBRMZ.E1, de 19 de dezembro de 2013. In: Bases Jurídico-Documentais do IGFEJ I.P., Lisboa. Disponível em: http://www.dgsi.pt/jtre.nsf/134973db04f39bf2802579bf005f080b/2106e3745d56821980257de10 056fd27?OpenDocument. Acesso em: 20 fev. 2020.

PORTUGAL. Acórdão do Tribunal da Relação de Coimbra, processo n. ${ }^{\circ}$ 1290/12.1PBAVR.C1, de 29 de janeiro de 2014. In: Bases Jurídico-Documentais do IGFEJ I.P., Lisboa. Disponível em: http: / / www.dgsi.pt/jtrc.nsf/8fe0e606d8f56b22802576c0005637dc/091165902546f4ad80257c740 03e6dee?OpenDocument. Acesso em: 20 fev. 2020.

PORTUGAL. Acórdão do Tribunal da Relação do Porto, processo n. ${ }^{\circ}$ 156/11.7GARSD.P1, de 22 de janeiro de 2014. In: Bases Jurídico-Documentais do IGFEJ I.P., Lisboa. Disponível em: http://www.dgsi.pt/jtrp.nsf/56a6e7121657f91e80257cda00381fdf/b7b44fe6dd194d5a80257c770 0416601?OpenDocument. Acesso em: 20 fev. 2020.

PORTUGAL. Acórdão do Tribunal da Relação do Porto, processo n. ${ }^{\circ}$ 648/12.0PIVNG.P1, de 10 de setembro de 2014. In: Bases Jurídico-Documentais do IGFEJ I.P., Lisboa. Disponível em: http://www.dgsi.pt/jtrp.nsf/56a6e7121657f91e80257cda00381fdf/28d944019fe9572180257d5e0 02cf5be?OpenDocument. Acesso em: 20 fev. 2020.

PORTUGAL. Acórdão do Tribunal da Relação de Guimarães, processo n. ${ }^{\circ}$ 591/11.0PBGMR-G1, de 10 de julho de 2014. In: Bases Jurídico-Documentais do IGFEJ I.P., Lisboa. Disponível em: http: //www.dgsi.pt/jtrg.nsf/86c25a698e4e7cb7802579ec004d3832/718002afb36807a180257d4f0 04b9f9a?OpenDocument. Acesso em: 20 fev. 2020.

PORTUGAL. Acórdão do Tribunal da Relação de Évora, processo n. ${ }^{\circ} 228 / 13.3 T A S T R$.E1, de 20 de janeiro de 2015. In: Bases Jurídico-Documentais do IGFEJ I.P., Lisboa. Disponível em: http: //www.dgsi.pt/jtre.nsf/134973db04f39bf2802579bf005f080b/6bfd2f864b23d41880257de100 582539?OpenDocument. Acesso em: $21 \mathrm{fev} .2020$.

PORTUGAL. Acórdão do Tribunal da Relação do Porto, processo n. ${ }^{\circ}$ 3299/14.1TAMTS.P1, 30 de setembro de 2015. In: Bases Jurídico-Documentais do IGFEJ I.P., Lisboa. Disponível em: http: / / www.dgsi.pt/jtrp.nsf/56a6e7121657f91e80257cda00381fdf / 46695696a87b292c80257edd0 052e3fa?OpenDocument. Acesso em: $21 \mathrm{fev} .2020$.

PORTUGAL. Acórdão do Tribunal da Relação de Guimarães, processo n. ${ }^{\circ}$ 77/14.1TAAVV.G1, de 2 de novembro de 2015. In: Bases Jurídico-Documentais do IGFEJ I.P., Lisboa. Disponível em: http://www.dgsi.pt/jtrg.nsf/86c25a698e4e7cb7802579ec004d3832/fe9e9c404499b03b80257efa0 039fdcd?OpenDocument. Acesso em: 21 fev. 2020.

PORTUGAL. Acórdão do Tribunal da Relação de Lisboa, processo n. ${ }^{\circ}$ 662/13.9GDMFR.L1, de 5 de julho de 2016. In: Procuradoria-Geral Distrital de Lisboa - Ministério Público, Lisboa.

Disponível em: http://www.pgdlisboa.pt/jurel/jur_mostra_doc.php?nid=5097\&codarea=57\&. Acesso em: 19 fev. 2020.

PORTUGAL. Acórdão do Tribunal da Relação do Porto, processo n. ${ }^{\circ}$ 18/15.9GAPRD.P1, de 7 de julho de 2016. In: Bases Jurídico-Documentais do IGFEJ I.P., Lisboa. Disponível em: 
ISSN 1981-3694

(DOI): $10.5902 / 1981369442646$

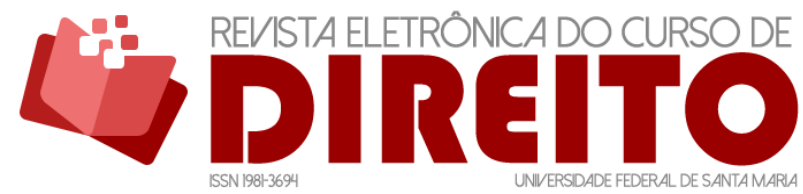

O CRIME DE VIOLÊNCIA DOMÉSTICA: ATO REITERADO OU NÃO, EIS A QUESTÃO

NUNO CAETANO LOPES DE BARROS POIARES

http://www.dgsi.pt/jtrp.nsf/56a6e7121657f91e80257cda00381fdf/c99b6c24a3986256802580250 045612d?OpenDocument. Acesso em: 19 fev. 2020.

PORTUGAL. Acórdão do Tribunal da Relação de Guimarães, processo n. ${ }^{\circ}$ 201/16.06GBBCL.G1, de 6 de fevereiro de 2017. In: Bases Jurídico-Documentais do IGFEJ I.P., Lisboa. Disponível em: http://www.dgsi.pt/jtrg.nsf/86c25a698e4e7cb7802579ec004d3832/b22cdeae54546906802580c7 005424b3?OpenDocument. Acesso em: 19 fev. 2020.

PORTUGAL. Acórdão do Tribunal da Relação de Lisboa, processo n. ${ }^{\circ} 3 / 16.0 P A P S T . L 1-9$, de 1 de junho de 2017. In: Bases Jurídico-Documentais do IGFEJ I.P., Lisboa. Disponível em: http://www.dgsi.pt/jtrl.nsf/33182fc732316039802565fa00497eec/533100ea5a275ebf8025813600 60bd7b?OpenDocument. Acesso em: 19 fev. 2020.

PORTUGAL. Acórdão do Tribunal da Relação de Coimbra, processo n. ${ }^{\circ}$ 663/16.5 PBCTB.C1, de 7 de fevereiro de 2018. In: Bases Jurídico-Documentais do IGFEJ I.P., Lisboa. Disponível em: http: / / www.dgsi.pt/jtrc.nsf/8fe0e606d8f56b22802576c0005637dc/fe62eef9a15eb0888025822f00 4d20ff?OpenDocument. Acesso em: 19 fev. 2020.

PORTUGAL. Acórdão do Tribunal da Relação da Guimarães, processo n. ${ }^{\circ} 121 / 15.5 G A V F L . G 1$, de 4 de junho de 2018. In: Bases Jurídico-Documentais do IGFEJ I.P., Lisboa. Disponível em: http://www.dgsi.pt/jtrg.nsf/86c25a698e4e7cb7802579ec004d3832/a90e43153a77645d802582ad 003df2fd?OpenDocument. Acesso em: 19 fev. 2020.

PORTUGAL. Acórdão do Tribunal da Relação de Évora, processo n. ${ }^{\circ}$ 9/17.5GBABF.E1, de 26 de julho de 2018. In: Bases Jurídico-Documentais do IGFEJ I.P., Lisboa. Disponível em: http: //www.dgsi.pt/jtre.nsf/134973db04f39bf2802579bf005f080b/1265873ec18fb1418025830d00 34a34b?OpenDocument. Acesso em: 19 fev. 2020.

PORTUGAL. Acórdão do Tribunal da Relação de Lisboa, processo n. ${ }^{\circ}$ 356/17.6GACSC.L1-3, de 10 de outubro de 2018. In: Bases Jurídico-Documentais do IGFEJ I.P., Lisboa. Disponível em: http://www.dgsi.pt/jtrl.nsf/33182fc732316039802565fa00497eec/cb1e03ee51b739a18025832e0 04c3394?OpenDocument. Acesso em: 19 fev. 2020.

PORTUGAL. Instrução n. ${ }^{\circ} 2 / 2014$ de 30.10.2014 - Inquéritos por crimes de violência doméstica para uso pelas Forças de Segurança. Ficha RVD-1L e Ficha RVD-2L. Ministério Público de Portugal. Disponível em: http://www.ministeriopublico.pt/destaque/instrucao-no-22014-daprocuradora-geral-da-republica. Acesso em: $18 \mathrm{fev} .2020$.

PORTUGAL. Diretiva n. ${ }^{\circ} 5 / 2019$, de 4 de dezembro - estabelece procedimentos específicos a observar pelos magistrados e agentes do Ministério Público na área da violência doméstica. In: Diário da República Eletrónico. Disponível em: https://dre.pt/home//dre/126870404/details/maximized. Acesso em: $18 \mathrm{fev} .2020$.

SILVA, Hugo Daniel da Cunha Lança. Já não te amo: o que fazemos à criança? Revista Eletrônica do Curso de Direito da UFSM, Santa Maria, RS, v. 14, n. 2, e34907, maio./ago. 2019. ISSN 19813694. DOI: http://dx.doi.org/10.5902/1981369434907. Disponível em: https://periodicos.ufsm.br/revistadireito/article/view/34907. Acesso em: 16 fev. 2020.

Artigo convidado / Publicado em 26.06.2020 


\section{COMO FAZER REFERÊNCIA AO ARTIGO (ABNT):}

POIARES, Nuno Caetano Lopes de Barros. O crime de violência doméstica: ato reiterado ou não, eis a questão. Revista Eletrônica do Curso de Direito da UFSM, Santa Maria, RS, v. 15, n. 1, e42646, jan./abr. 2020. ISSN 1981-3694. DOI: http://dx.doi.org/10.5902/1981369442646. Disponível em: https://periodicos.ufsm.br/revistadireito/article/view/42646. Acesso em: dia mês. ano.

\section{Direitos autorais 2020 Revista Eletrônica do Curso de Direito da UFSM}

Editores responsáveis: Rafael Santos de Oliveira e Angela Araujo da Silveira Espindola

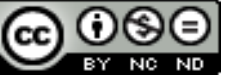

Esta obra está licenciada com uma Licença Creative Commons Atribuição-NãoComercial-SemDerivações 4.0 Internacional.

\section{SOBRE O AUTOR}

\section{NUNO CAETANO LOPES DE BARROS POIARES}

Oficial Superior (Intendente) da Polícia de Segurança Pública, professor universitário e investigador integrado do ICPOLISCPSI. Comandante do Corpo de Alunos do Instituto Superior de Ciências Policiais e Segurança Interna, Lisboa, Portugal (desde 2019). Diretor do ICPOL - Unidade de I\&D do ISCPSI, classificada com MUITO BOM pela FCT - Fundação para a Ciência e a Tecnologia (2017-2019). Coordenador do Curso de Mestrado em Ciências Policiais (Criminologia e Investigação Criminal/Gestão da Segurança/Segurança Interna) do ISCPSI, Lisboa (desde 01.07.2016). Diretor do Departamento de Científico de Ciências Policiais do ISCPSI (desde 2019). Co-Coordenador da Secção Temática "Segurança, Defesa e Forças Armadas" da Associação Portuguesa de Sociologia (2018-2022). Professor Auxiliar de Criminologia e de Sociologia do Desvio e da Violência (desde 2010), Metodologia das Ciências Sociais (2017-18), Técnica de Serviço Policial III e IV (desde 2017) e Comando e Liderança (desde 2018) no Instituto Superior de Ciências Policiais e Segurança Interna (Lisboa) e Professor Adjunto Convidado de Introdução ao Direito, Direito Penal, Processo Penal, Contraordenações, Resolução Alternativa de Litígios, Teoria Geral do Direito Civil e Sociologia do Direito no Instituto Politécnico de Beja. Formador de Direito Processual Penal no VIII Estágio Probatório da Carreira de Investigação e Fiscalização do Serviço de Estrangeiros e Fronteiras (SEF). Professor Convidado em diversas instituições e estabelecimentos de ensino: FDUL, FDUC, FDULHT, SEF, UAL, ISSSB, U. Jean Piaget de Angola, Instituto de Ciências Policiais de Angola, ISCTAC-Moçambique, Instituto Politécnico de Beja, Escola Superior de Enfermagem S. Francisco das Misericórdias, Lisboa; Universidade Moderna, etc. Orientador, presidente ou arguente de mais de 6 dezenas de júris de doutoramento e mestrado. Formado pelo Colégio Militar, Lisboa, Portugal (19851994). Licenciatura pré-Bolonha em Ciências Policiais (ISCPSI, 1999) e em Direito/Ciências Jurídico-Forenses (FDULHT, 2009). Estudos Doutorais (18 valores, 2012), mestrado (com a menção máxima, 2005) e pós-graduação (16 valores, 2003) em Sociologia pela Universidade de Évora. Doutor em Sociologia Política e do Direito aprovado com distinção por unanimidade (classificação máxima) pelo ISCTE-IUL (23.07.2015). Tese: "Políticas de segurança e as dimensões simbólicas da lei: o caso da violência doméstica em Portugal" (2014). Título de especialista em Direito Penal pelo Conselho Técnico-Científico do Instituto Politécnico de Beja (18.07.2018). Título de especialista em Direito, com provas públicas ocorridas em 13.02.2020, nos termos do Decreto-Lei n. ${ }^{\circ}$ 206/2009, de 31 de agosto (IPLisboa, IPLeiria e IPBeja). Atualmente é mestrando em Direito e Prática Jurídica (especialidade de Direito Penal) pela Faculdade de Direito da Universidade de Lisboa (2019-2021). Frequentou inúmeros cursos profissionais, onde se incluem três ações de formação no domínio das ciências jurídico-criminais promovidas pelo Centro de Estudos Judiciários, bem como na área do comando, liderança, coaching, recursos humanos, gestão de incidentes táticos, entre outros. Experiência de serviço em Moçambique, Hungria-Budapeste, Qatar, Angola e Bruxelas. Consultor em diversos organismos na área dos Recursos Humanos, Educação e da Violência na Juventude. Conheceu inúmeras realidades distintas (Qatar, Moçambique, Hungria, Macau, Hong-Kong, China, Angola, Bélgica, Holanda, Principado de Andorra, França, Espanha, Marrocos, Ceuta e República Dominicana). Tem orientado dissertações de mestrado e teses de doutoramento. Autor e co-autor de diversos livros, artigos em revistas com arbitragem científica, crónicas e comunicações. 